\title{
Cost-Efficiency of Medication Safety Program at Public Hospital, Riyadh, Saudi Arabia
}

\author{
Yousef Ahmed Alomi* iD, The \\ Former General Manager of General \\ Administration of Pharmaceutical Care, \\ Former Head, National Clinical Pharmacy \\ and Pharmacy Practice. Former Head, \\ Pharmacy R\&D Administration, Ministry of \\ Health, Riyadh, SAUDI ARABIA.
}

Mona Awad Alanazi, IV admixture and TPN units, Pharmacy services, Prince Mohammad Bin Abdulaziz Hospital Riyadh, SAUDI ARABIA.

Radi Abdullah Alattyh, General Administration of Pharmaceutical Care, Ministry of Health, Riyadh, SAUDI ARABIA.

Fatimah Ali Albusalih, College of Clinical Pharmacy, Imam Abdulrahman Bin Faisal University (University of Dammam) Dammam, SAUDI ARABIA.

\section{Correspondence:}

Dr. Yousef Ahmed Alomi, The Former General Manager of General Administration of Pharmaceutical Care, Former Head, National Clinical Pharmacy and Pharmacy Practice, Former Head, Pharmacy R\&D Administration, Ministry of Health, Riyadh-11392, SAUDI ARABIA.

Phone no: +966 504417712

E-mail:yalomi@gmail.com

Received: 17-1-2019

Approved: 15-4-2019

Copyright: ๑ the author(s),publisher and licensee Pharmacology, Toxicology and Biomedical Reports. This is an open-access article distributed under the terms of the Creative Commons Attribution NonCommercial License, which permits unrestricted non-commercial use, distribution, and reproduction in any medium, provided the original work is properly cited.

This is an open access article distributed under the terms of the Creative Commons Attribution-NonCommercial-ShareAlike 4.0 License

Access this article online

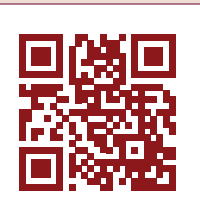

www.ptbreports.org

DOI: 10.5530/PTB.2019.5.29

\begin{abstract}
Objectives: Medication safety program started at Riyadh city of Ministry of Health in 2014. Identifying, resolving and preventing drug therapy problems are the unique contributions of the pharmaceutical care practitioner. The research aimed to estimate cost-efficiency of Medication Safety program at the hospital in East province, Saudi Arabia by using American model of pharmacist intervention cost avoidance. Methods: This cross-sectional study with a 9-month recruitment period was conducted in a 300-bed public hospital through preventing and documentation of medication errors in adults and pediatrics at Ministry of Health hospitals in 2015. The program led by trained pharmacist and delivered basic patient safety in medical education to all healthcare professionals. The predictable cost calculated using International Study Model, expressed in USD, the cost measured were the expected results of medication errors outcome if not stopped; starting from physician visit, additional laboratory test, further treatment, hospital admission and critical care admission to death stage. Results: The total number of prevented medication errors were 3,378 at 805 prescribed to 805 patients with an estimated cost avoidance of avoiding medication errors was $(98,195.97$ USD) for the study period and $(10,910$ USD) per month. The pharmacist avoided medication errors with estimated cost avoidance of drugrelated problem (29 USD) per each mistake and (122 USD) per prescription and patient. The most type inquiries estimated cost avoidance was prescribing stage 86,939.05 USD (99.86\%), followed by drugrelated errors 7,061.26 USD (7.2\%) and dosage form-related errors 6,084.98 USD (6.2\%). The highest drug of cost avoidance were Musculoskeletal and joint disease (8,397.2 USD) followed by Infections $(5,731.17$ USD) and Nutrition (4,717.99 USD), while the largest drug of cost avoidance was Paracetamol Injection (5,812.17 USD), followed by oral Ferrous Sulfate (3,562.79 USD) and Ceftriaxone $1 \mathrm{~g}(2,861.70$ USD). Conclusion: Medication safety program is a cost-efficiency simulation at the public hospital in Saudi Arabia, prevents medication disasters, improve patient safety. Increasing drug safety program associated with preventing drug-related problems and cost avoidance simulation for Healthcare development and better care and better patient consequences.
\end{abstract}

Key words: Cost-efficiency, Medication, Safety, Public, Hospital, Ministry of Health, Riyadh, Saudi Arabia.

\section{INTRODUCTION}

Quality patient care is a significance issue in all healthcare sectors; however, clinical errors are known to compromise patient safety. After recent directing events in which preventable failures in healthcare were recognized, patient safety remains high on the clinical and policy agenda in health systems. The established paradigm for studying medical decision-making is definitely attempted in a setting of vulnerability concerning the results and saving cost of programs and interferences of health care. Thusly, two arrangements of related choices should be taken: (1) those concerning proper administration arrangement based on existing data (from the earlier choice); and (2)benefit-cost analyses those which are calling for additional information collection in order to overcome earlier errors from a previous decision. ${ }^{1}$ The choice regarding prolific service arrangement, based on collected data, includes individual the endorsement related with the best choice result (from the earlier decision). ${ }^{1,2}$ Inside the assessment of health technologies, choice settlements are the costs and impacts related with the considered interventions. Usually, these adjustments have been merged to frame Incremental Cost-Effectiveness Ratio (ICER) with the ideal involvement recognized as the one that produces the biggest ICER that falls under an external set limit. ${ }^{3}$ By unequivocally consolidating, the choice settlements (effects and costs) can form a net benefit for every intervention ( $t$ ) joined either in health outcomes or financial terms. ${ }^{4,5}$ Drug-Related Problems (DRPs), its health related and monetary weights which include Medication Errors (MEs), Adverse Drug Reactions (ADRs) and Adverse Drug Events (ADEs) have brought about fundamentals to guarantee enhanced medicine safety Programs. ${ }^{6,7}$ National Patient Safety Goal (NPSG) focuses on the risk points of medication reconciliation. The elements of performance in this NPSG are planned to help organizations reduce negative patient outcomes associated with medication inconsistencies. ${ }^{8}$ Measurement of DRPs as well as its detection are basic to the distinctive proof of fundamental causes and making of patient care plans. ${ }^{9,10}$

The study conducted by Bates DW et al. the incidence of adverse drug events was 6.5 per 100 admissions and $28 \%$ were preventable. The ADEs and preventable contributed with an increased length of stay of 2.2 to 4.6 days and to an increase in cost of medication by 2,595 to 4,685 USD. ${ }^{11}$ The cost showed in this study is far less than the cost incurred by the Saudi hospital during the 
conduct of the study. Another Study conducted by Classen DC et al. found that medication errors increased the cost of medication at the hospital by 2,262 USD and an increased risk of death of 1.88 fold. ${ }^{12}$ The other studies in other countries could be unrealistic as the cost of medications differ across countries - this is according to the country's health system. Rottenkolber D et al. conducted a similar study where they found that the cost of medication errors were 1,033 USD for each person. ${ }^{13}$ There are few studies conducted related on cost impact of medication safety program. However, Chen CC et al. revealed that the benefit/cost ratio increased from 4.29 to 9.36 and average admission days decreased by 2 days after the on-ward deployment of a clinical pharmacist. ${ }^{14}$ In addition, the total cost avoidance was 103,073,160 - 224,590,140 US \$ annually. Another study by Najafzadeh $\mathrm{M}$ et al. found $52 \%$ reduced of medication reconciliation discrepancies and total saved was 175,306 US $\$$ in the study period. ${ }^{15}$ Medication reconciliation by pharmacists at hospital discharge is a possible strategy to diminish medication discrepancies and consequent ADEs. In Saudi Arabia, because of the increasing problem of medical errors and expanding media attention, health associations has been presently seeking after efforts to enhance quality and safety of overall medicinal services. A few activities have been implemented to boost safety mostly through setting up roles and starting accreditation plans. ${ }^{8}$ A recent study conducted by Alomi YA et al. To explore the cost of drug related problems in Saudi Arabia from patients and healthcare professional viewpoints. The study found the estimated average cost per each medication error problem and per patient cost were (762.67) and (1347.38) respectively. ${ }^{16}$ To the best of our knowledge, no comprehensive scientific study has explored these challenges and barriers in all Healthcare Facilities (HCFs) across the Kingdom of Saudi Arabia (KSA). The research aimed to estimate cost-efficiency of Medication Safety program at the hospital in Riyadh city, Saudi Arabia by using American model of pharmacist intervention cost avoidance.

\section{METHODS}

This cross-sectional study with a 9-month recruitment period was conducted in a 300-bed public hospital through preventing and documentation of medication errors in adults and pediatrics at Ministry of Health hospitals at Riyadh, Saudi Arabia in 2015. The study included inpatient sections of the hospital. The hospital services cover a range of medical offerings from basic health care to Adults Endocrinology, Adults Nephrology Pediatrics, Adults Cardiology, Adults Internal Medicine, Adults Surgery, Adults critical care, The Neonatal Intensive Care Unit (NICU), The Pediatric Intensive Care Unit, Obstetrics and Gynecology in addition to ambulatory care services and emergency services. Also, the hospital pharmacy offers very comprehensive pharmaceutical services including inpatient pharmacy, ambulatory care pharmacy, Total Parenteral Nutrition (TPN) services, drug information services and computerized physician order entry system inpatient and outpatient units. Also, the clinical pharmacist shared in the round with the medical team and patient counseling clinics. Before three years in 2014, the pharmacy department established medication safety program. ${ }^{17}$ Medication safety program started at Riyadh Region in 2013. National medication safety program of Ministry of Health and Central committee of medication committee it headed by first author and Riyadh Regional Medication safety committee headed by second author. In particular, a hospital medication safety program managed by part-time pharmacist and the program consisted of medication officer and local committee of medication safety.

The officer monitors all medication errors, adverse drug reaction, drug quality system inside the hospital, Institute Safety Medication Practice (ISMP) guidelines, ${ }^{18-21}$ local standard of accreditation body (Saudi Central Board of Health Care Accreditation) standards and medication safety of Joint commission of Hospital accreditation from United States of America. ${ }^{8,22}$ They also felt accountable for medication safety course to all health care professional, physician, pharmacist, nurses etc. and report all medication safety related issues to higher administration and $\mathrm{MOH}$. Medication officers are responsible for documenting Medication Errors (MEs), Adverse Drug Reactions (ADRs) using the different forms of MEs and ADRs forms. All errors or unforeseen events related with the medication system or a step in the medication process shall be reported using the medication error notification form/medication error sheet whether or not the error reached the patient. The medical error form consists of 2 parts and 40 items including types and causes of medical errors. The form mainly consisted of patient information, description of errors - date and time, medical product involved in the event, impact of the error, consequences, intervention, the sources of medication errors and qualification of committing errors. Suspected medications, drug classification, stage of medication orders, details of reporter, route of administration for medication, the type of medication errors, description and causes of errors, agreement to prevent the errors and the significance of medication errors by using National Coordinating Council for Medication Error Reporting and Prevention (NCCMERP) system. ${ }^{23}$ The likely cost calculated using International Study Model, expressed in USD, the cost measured were the expected results of drug-related problems outcome of drug information services if not stopped and were not answered; starting from physician visit, additional laboratory test, more treatment, hospital admission and critical care admission to death stage. ${ }^{24,25}$ One way sensitivity analysis was done for a discount of prices list and variety of wage cost with 10-20\%. The format analyzed through the Microsoft Excel Sheet Version $10^{\text {th }}$. The study was conducted according to the ethics guidelines set out in the Declaration of Helsinki and consent from was obtained from the institution.

\section{RESULTS}

The total number of prevented medication errors were 3,378 at 805 prescribed to 805 patients with an estimated cost avoidance of avoiding medication errors was $(98,195.97$ USD) for the study period and $(10,910$ USD) per month. The pharmacist avoided medication errors with estimated cost avoidance of drug-related problem (29 USD) per each mistake and (122 USD) per prescription and patient. The highest cost avoidance $(89.1 \%)$ came from predictable age (18-more than 65) while (8.28\%) from pediatrics The most type inquiries estimated cost avoidance was prescribing stage 86,939.05 USD (99.86\%), while the most cost avoidance of type of errors was prescriber related and general errors $83,707.98$ USD (85.2\%), followed by drug-related errors 7,061.26 USD (7.2\%) and dosage form-related errors 6,084.98 USD (6.2\%) (Table 1).

The most cost avoidance related to subtype of error was prescriber name (missing/unclear) 22,357.51 USD (22.768\%), followed by prescriber signature (missing/unclear) 21,337.93 USD (21.730\%) and prescription data (unclear) 19,218.41 USD (19.571\%) (Table 2-4). The highest drug of cost avoidance was Musculoskeletal and joint disease (8,397.2 USD) followed by Infections (5,731.17 USD) and Nutrition (4,717.99 USD), while the largest drug of cost avoidance was Paracetamol Injection (5,812.17 USD), followed by oral Ferrous Sulfate (3,562.79 USD) and Ceftriaxone $\lg (2,861.70$ USD) (Table 5 and 6).

\section{DISCUSSION}

This study established the cost benefit and prevention of medication errors due to the interference of pharmacist at the hospital in Riyadh city, Saudi Arabia. The number of pharmacist interventions in medication orders greatly enlarged after the on-ward arrangement of pharmacist, which resulted in a substantial cost benefit, fewer admission days and probably fewer MEs. There were obviously more interventions about medication duration or quantity, ideas of more appropriate medications 
Alomi, et al.: Cost-Effectiveness of Medication Safety at Public Hospital, Saudi Arabia

Table 1: Documented cost avoidance related to the age of Patient.

\begin{tabular}{|l|c|c|c|c|}
\hline $\begin{array}{l}\text { Answer } \\
\text { Options }\end{array}$ & $\begin{array}{c}\text { Response } \\
\text { Count }\end{array}$ & Cost (USD) & $\begin{array}{c}\text { Cost (USD) } \\
\text { percentages }\end{array}$ & $\begin{array}{c}\text { Average cost } \\
\text { per patient } \\
\text { for each } \\
\text { stage }\end{array}$ \\
\hline 30 Days & 8 & 204.09 & $0.45 \%$ & 25.51 \\
\hline $\begin{array}{l}1 \text { month - } \\
6 \text { years }\end{array}$ & 27 & 993.25 & $2.20 \%$ & 36.79 \\
\hline 6 - 12 years & 35 & $2,544.78$ & $5.63 \%$ & 72.71 \\
\hline 12 -18 years & 27 & $1,188.9$ & $2.63 \%$ & 44.03 \\
\hline $18-40$ years & 158 & $13,833.2$ & $30.59 \%$ & 87.55 \\
\hline $40-65$ years & 156 & $23,977.99$ & $53.02 \%$ & 153.71 \\
\hline $\begin{array}{l}\text { More than } 65 \\
\text { years }\end{array}$ & 31 & $2,484.7$ & $5.49 \%$ & 80.15 \\
\hline Total & $\mathbf{4 4 2}$ & $\mathbf{4 5 , 2 2 6 . 9 1}$ & & \\
\hline $\begin{array}{l}\text { Answered } \\
\text { question }\end{array}$ & $\mathbf{3 6 3}$ & & & \\
\hline $\begin{array}{l}\text { Skipped } \\
\text { question }\end{array}$ & & & \\
\hline \multicolumn{2}{|l|}{ Total cost with $10 \%$ discount } & $\mathbf{4 0 , 7 0 4 . 2 2}$ & & \\
\hline Total cost with 20\% discount & $\mathbf{3 6 , 1 8 1 . 5 3}$ & & \\
\hline
\end{tabular}

Table 2: Documented cost avoidance related to stages involved.

\begin{tabular}{|l|c|c|c|}
\hline Answer Options & $\begin{array}{c}\text { Response } \\
\text { Count }\end{array}$ & $\begin{array}{c}\text { Cost } \\
\text { Avoidance } \\
\text { (USD) }\end{array}$ & $\begin{array}{c}\text { Cost Avoidance } \\
\text { (USD) } \\
\text { percentages }\end{array}$ \\
\hline Prescribing & 705 & $86,939.05$ & $99.86 \%$ \\
\hline Preparing & 3 & 65.52 & $0.08 \%$ \\
\hline Dispensing & 2 & 30.35 & $0.03 \%$ \\
\hline Transcribing & 0 & 00.00 & $0.00 \%$ \\
\hline Administering & 1 & 26.17 & $0.03 \%$ \\
\hline Monitoring & 0 & 00.00 & $0.00 \%$ \\
\hline Total & & $\mathbf{8 7 , 0 6 1 . 0 9}$ & \\
\hline answered question & $\mathbf{7 1 1}$ & & \\
\hline skipped question & $\mathbf{9 4}$ & & \\
\hline Total cost with 10\% discount & & $\mathbf{7 8 , 3 5 4 . 9 8}$ & \\
\hline Total cost with 20\% discount & & $\mathbf{6 9 , 6 4 8 . 8 7}$ & \\
\hline
\end{tabular}

Table 3: Documented cost avoidance related to the type of errors.

\begin{tabular}{|c|l|c|c|}
\hline$\#$ & Type of Error & Cost avoidance & Percent \\
\hline 1 & Patient-Related error & 0.00 & $0.0 \%$ \\
\hline 2 & Prescriber-Related and general errors & $83,707.98$ & $85.2 \%$ \\
\hline 3 & Drug-Related errors & $7,061.26$ & $7.2 \%$ \\
\hline 4 & Dosage form-Related errors & $6,084.98$ & $6.2 \%$ \\
\hline 5 & Therapeutics-related errors & $1,341.75$ & $1.4 \%$ \\
\hline \multicolumn{2}{|l|}{ Total } & $\mathbf{9 8 , 1 9 5 . 9 7}$ & $\mathbf{1 0 0 . 0 \%}$ \\
\hline \multicolumn{2}{|l|}{ Total cost with 10\% discount } & $\mathbf{8 8 , 3 7 6 . 3 7}$ & \\
\hline \multicolumn{2}{|l|}{ Total cost with 20\% discount } & $\mathbf{7 8 , 5 5 6 . 7 8}$ & \\
\hline
\end{tabular}

Table 4: Documented cost avoidance according to the sub-type of errors.

\begin{tabular}{|c|c|c|}
\hline Type-Related error & Cost & Percentage \\
\hline \multicolumn{3}{|l|}{ Patient-Related error } \\
\hline Diagnosis not written & - & - \\
\hline Patient allergy & - & - \\
\hline Patient body weight not written & - & - \\
\hline Patient age not written & - & - \\
\hline Wrong patient & - & - \\
\hline Non- existing patient & - & - \\
\hline \multicolumn{3}{|l|}{ Prescriber-Related and general errors } \\
\hline Prescriber name is missing / unclear & $22,357.51$ & $22.768 \%$ \\
\hline \multicolumn{3}{|l|}{ Prescriber ID\# is missing /unclear } \\
\hline Prescriber signature missing / unclear & $21,337.93$ & $21.730 \%$ \\
\hline $\begin{array}{l}\text { Prescriber not follow policy of prescribing } \\
\text { (write dose / weight) }\end{array}$ & - & - \\
\hline Wrong transcription & - & - \\
\hline Department is missing / unclear & $10,977.13$ & $11.179 \%$ \\
\hline Poor handwriting & $6,373.10$ & $6.490 \%$ \\
\hline Wrong abbreviations & $3,443.89$ & $3.507 \%$ \\
\hline Prescription data unclear & $19,218.41$ & $19.571 \%$ \\
\hline \multicolumn{3}{|l|}{ Drug-Related errors } \\
\hline Incorrect dose-overdosing & - & - \\
\hline Dose omitted & - & - \\
\hline Duration-inadequate & - & - \\
\hline Dosing frequency-excessive & $2,282.34$ & $2.324 \%$ \\
\hline Incorrect dose-under dosing & - & - \\
\hline $\begin{array}{l}\text { Amount of drug missing / unclear / } \\
\text { insufficient }\end{array}$ & 26.62 & $0.027 \%$ \\
\hline Drug name is missing /incorrect & $4,320.80$ & $4.400 \%$ \\
\hline Duration-excessive & 187.04 & $0.190 \%$ \\
\hline Dosing frequency-inadequate & 244.45 & $0.249 \%$ \\
\hline Incorrect drug & - & - \\
\hline \multicolumn{3}{|l|}{ Dosage Form-Related Errors } \\
\hline General dosage form-Related Errors & $1,795.38$ & $1.828 \%$ \\
\hline Incorrect /unclear formulation & 39.94 & $0.041 \%$ \\
\hline Incorrect / unclear route & 579.31 & $0.590 \%$ \\
\hline Incorrect / unclear strength & $3,670.35$ & $3.738 \%$ \\
\hline \multicolumn{3}{|l|}{ Therapeutics-Related Errors: } \\
\hline Drug-drug interaction & 576.35 & $0.587 \%$ \\
\hline Drug-Disease interaction & - & - \\
\hline Therapeutics duplication & 416.88 & $0.425 \%$ \\
\hline IV preparation without label & - & - \\
\hline Drug Contraindications & 132.49 & $0.135 \%$ \\
\hline Infective Therapy & 216.03 & $0.220 \%$ \\
\hline Total & $98,195.97$ & \\
\hline
\end{tabular}

and the finding of MEs after the pharmacist's contribution. The benefitcost analysis doubled after the on-ward deployment of a pharmacist through medication safety program.

The general administration of pharmaceutical care underway pharmacy practice as part of pharmacy strategic plan in Saudi Arabia. The 
Table 5: The most medications classes of the documented cost avoidance.

\begin{tabular}{|c|l|c|c|}
\hline$\#$ & Medication classes & $\begin{array}{c}\text { No of } \\
\text { occurrences } \\
\text { medication had } \\
\text { errors }\end{array}$ & $\begin{array}{c}\text { Cost } \\
\text { avoidance } \\
\text { (USD) }\end{array}$ \\
\hline 1 & $\begin{array}{l}\text { Musculoskeletal and joint } \\
\text { disease }\end{array}$ & 60 & $8,397.2$ \\
\hline 2 & Infections & 88 & $5,731.17$ \\
\hline 3 & Nutrition & 41 & $4,717.99$ \\
\hline 4 & Gastrointestinal & 37 & $1,782.6$ \\
\hline 5 & Cardiovascular & 44 & $1,295.44$ \\
\hline 6 & $\begin{array}{l}\text { Immunological products and } \\
\text { vaccines }\end{array}$ & 13 & $1,089.44$ \\
\hline 7 & Malignant disease & 7 & 240.62 \\
\hline 8 & Central nervous system & 11 & 224.45 \\
\hline 9 & Endocrine system & 9 & 254.8 \\
\hline 10 & Ear, Nose and oropharynx & 2 & 56.52 \\
\hline 11 & Urinary tract disorders & 2 & 26.17 \\
\hline Total & & 314 & \\
\hline
\end{tabular}

Table 6: The most medications of the documented cost avoidance.

\begin{tabular}{|c|l|c|c|}
\hline$\#$ & Medication & Dosage form & Cost avoidance \\
\hline 1 & Paracetamol & Injection & $5,812.17$ \\
\hline 2 & FerrousSulfate & Oral & $3,562.79$ \\
\hline 3 & Ceftriaxone 1g & Injection & $2,861.70$ \\
\hline 4 & Omeprazole $40 \mathrm{mg}$ & Onjection & $1,219.18$ \\
\hline 5 & Paracetamol & Injection & 894.42 \\
\hline 6 & Alfacalcidol & Injection & 425.98 \\
\hline 7 & Anti-rabies & Oral & 241.87 \\
\hline 8 & Cefuroxime 250mg & Oral & 185.73 \\
\hline 9 & Ondansetron 4mg & Injection & 169.56 \\
\hline 10 & Enoxaparin & Oral & 167.93 \\
\hline 11 & Metronidazole 500mg & Oral & 163.75 \\
\hline 12 & Cefuroxime 500mg & Oral & 141.76 \\
\hline 13 & Ciprofloxacin500mg & Injection & 141.76 \\
\hline 14 & Erythropoietin & Injection & 135.03 \\
\hline 15 & Cefuroxime 750mg & Oral & 104.68 \\
\hline 16 & Omeprazole 40mg ORAL & Injection & 86.87 \\
\hline 17 & Ciprofloxacin400mg & Injection & 56.52 \\
\hline 18 & Piperacillin/Tazobactam & Injection & 54.89 \\
\hline 19 & Ondansetron & & \\
\hline & & & \\
\hline
\end{tabular}

Pharmacoeconomic program was one the complete program. The current study was part of the Pharmacoeconomic study to explore the cost impact of medication safety with prevention of drug mistake. The study showed that the pharmacist had huge cost avoidance related drug problems and to prevent medication errors. Comparably, research has shown that medication errors occur at physician order which considered to be a avoidable beside huge annual cost. The cost avoidance of prevented medication errors in our study look like what reported previously study by Chen $\mathrm{C}$ et al. ${ }^{14}$ The predictable cost saving was calculated conventionally by a 1 day cost of the intervened medications. Moreover, the estimated cost avoidance was also calculated orthodoxly based on only 2 extra days of admission if ADEs occurred, although this may have resulted in more than 2 days of admission according to the Chen $\mathrm{C}$ et al. ${ }^{11}$ Other study by Najafzadeh $\mathrm{M}$ et al. found contrasted from our results. ${ }^{15}$ The size of cost avoidance observed in studies is likely to depend on the settings in which the economic evaluation was conducted beside it likely to depend on the health care discipline, intensity of care, data collection methods and cost analysis.

In the study, the most cost avoidance came from prescribing stage because most of medical errors were related to the prescribing stage (prescriber related medication errors). During this period, the hospital did not implement e-prescribing, drug altering system or clinical decision support system to prevent medication errors. The highest categories of prescription cost avoidance was muscle and joint specially pain management, nutrition and antibiotics. Medications for pain management had several adverse drugs reaction and very to committing error. The majority of these errors were "wrong strength" and "wrong dosage". That's impact of complications have a significant impact on total health care costs. Similar complications occurred in the medications for nutrition or antibiotics used (top cost avoidance). However, other studies highlighted that the antimicrobials have to be in the top of most commonly group of drugs involved. ${ }^{26,27}$

The majority of findings was problematic to compare with previous studies because rarely existed of research variables and to the best of our knowledge, there is no study relating to this. The study showed excellent role of pharmacist through prevention of medication errors. The pharmacists practicing under this program are in a better position to impact use of medications, prevent unwanted side effects and financially benefits. Therefore, this integration presents an opportunity for clinical pharmacist to contribute to the medical Institute. Composed they pursued a low-tech, low-cost strategy for reaching their goal. The cost avoidance related of pharmacist impact is part of new pharmacy strategic planning with new vision 2030 in Kingdom of Saudi Arabia. ${ }^{28-29}$

\section{CONCLUSION}

The pharmacists play a very important role, not only in medication safety, but also in cost saving. The implementation of medication safety program is reasonable. It prevented medication related problems and improve patient's clinical outcomes. Besides, the program prevents additional economic burden on healthcare system at Ministry of Hospitals in Kingdom of Saudi Arabia. Although, there is considerable opportunity for further improvement.

\section{ACKNOWLEDGEMENT}

None.

\section{CONFLICT OF INTEREST}

The authors declare no conflict of interest.

\section{ABBREVIATIONS}

ICER: Incremental cost-effectiveness ratio; DRP: Drug-Related Problems; MEs: Medication Errors; ADR: Adverse Drug Reactions; ADEs: Adverse Drug Events; NPSG: National Patient Safety Goal; USD: United State Dollars; CPOE: Computerized Physician Order Entry; MOH: Ministry of Health; HCFs: Healthcare Facilities; KSA: Kingdom of Saudi Arabia; USD: United State Dollars; NICU: Neonatal Intensive Care Unit; TPN: Total parenteral nutrition; ISMP: Institute Safety Medication Practice; NCCMERP: National Coordinating Council for Medication Error Reporting and Prevention. 


\section{ORCID ID}

\section{Yousef Ahmed Alomi, (D) https://orcid.org/0000-0003- 1381-628X}

\section{REFERENCES}

1. Fenwick $E$, Claxton $K$, Sculpher M, Briggs A. Improving the efficiency and relevance of health technology assessment: The role of iterative decision analytic modelling. Centre for Health Economics, University of York. 2000. Cited Dec 42018.

2. Thompson KM, Graham JD. Going beyond the single number: Using probabilistic risk assessment to improve risk management. Hum Ecol Risk Assess. 1996;2(4):1008-34

3. Karlsson G, Johannesson M. The decision rules of cost-effectiveness analysis. Pharmacoeconomics. 1996;9(2):113-20.

4. Claxton K, Posnett J. An economic approach to clinical trial design and research priority-setting. Health Econ. 2018;5(6):513-24.

5. Stinnett AA, Mullahy J. Net health benefits: A new framework for the analysis of uncertainty in cost-effectiveness analysis. Med Decis Mak. 1998;18(2_suppl): S68-80

6. Institute of Medicine (US) Committee on Quality of Health Care in America. To Err is Human: Building a Safer Health System. National Academies Press, Washington, D.C. 2000. Cited Dec 4 2018. Available from: http://www.nap.edu/ catalog/9728.

7. Kelly WN. Prescribed medications and the public health: Laying the foundation for risk reduction. CRC Press. 2006. 2018;355.

8. The Joint Commission. 2016 Comprehensive Accreditation Manual for hospitals. Joint Commission Resources. 2016. Available from: http://www.mitsstools.org/ uploads/3/7/7/6/3776466/psc_for_web.pdf.

9. Santell JP, Hicks RW. Medication errors involving geriatric patients. Jt Comm J Qual patient Saf. 2005;31(4):233-8.

10. Resar RK, Rozich JD, Classen D. Methodology and rationale for the measure ment of harm with trigger tools. Qual Saf Health Care. 2003;12 (Suppl 2):ii39-45.

11. Bates DW, Cullen DJ, Laird N, Petersen LA, Small SD, Servi D, et al. Incidence of adverse drug events and potential adverse drug events: Implications for prevention. ADE Prevention Study Group: JAMA. 1995;274(1):29-34.

12. Classen DC, Metzger J. Improving medication safety: the measurement conundrum and where to start. Int J Qual Heal care. 2003;15 (Suppl 1):i41-7.

13. Rottenkolber D, Hasford J, Stausberg J. Costs of adverse drug events in German hospitals - A microcosting study. Value Heal. 2012;15(6):868-75.

14. Chen CC, Hsiao FY, Shen LJ, Wu CC. The cost-saving effect and prevention of medication errors by clinical pharmacist intervention in a nephrology unit. Medicine. 2017;96(34):e7883
15. Najafzadeh M, Schnipper JL, Shrank WH, Kymes S, Brennan TA, Choudhry NK. Economic value of pharmacist-led medication. Am J Manag Care. 2016;22(10):654-61.

16. Alomi YA, Al-shaibani AS, Alfaisal G, Alasmi NM. Cost analysis of drug-related problems in Saudi Arabia: Patients' and healthcare providers' perspective. J Pharm Pract Community Med. 2018;4(2):107-12.

17. Alomi YA. National Medication Safety Program at Ministry of Health in Saudi Arabia. J Pharmacovigil. 2015;3(5):e145.

18. Adams AJ, Hauser RB, Kayden C, Landis W, McAntee S, McDermott J, et al. 2017 ISMP Medication Safety Self Assessment ${ }^{\circledR}$ for Community/Ambulatory Pharmacy. 2017. Available from: https://www.ismp.org/sites/default/files/attachments/2018-01/ISMP117C-Pharma\%20SA-FINAL\%20020317.pdf.

19. Institute for Safe Medication Practices. 2011 ISMP Medication Safety Self Assessment for Hospitals. Key Definitions. 2011;1-4. Available from: http:// ismp.org/selfassessments/Hospital/2011/definitions.pdf

20. ISMP International Medication Safety Self Assessment ${ }^{\circledR}$ for Oncology. 2012. Available from: https://www.ismp.org/assessments/international-oncology.

21. Conners J, Dager W, Evan M, Gulseth M, Jenkins RWM. 2017 ISMP Medication Safety Self Assessment for Antithrombotic Therapy. Medication Safety Self Assessment for Antithrombotic Therapy. 2017;1-26. Available from: https:// www.ismp.org/sites/default/files/attachments/201711/2017_ISMP_Antithrombotic_Self_Assessment.pdf.

22. Medication Management. In: National Hospital Standards. $2^{\text {nd }}$ Editio. Saudi Central Board for Accreditation of Healthcare Institutions. 2015;194-211.

23. Hartwig SC, Denger SD, Schneider PJ. Severity-indexed, incident report-based medication error-reporting program. Am J Hosp Pharm. 1991;48(12):2611-6.

24. Ling JM, Mike LA, Rubin J, Abraham P, Howe A, Patka J, et al. Documentation of pharmacist interventions in the emergency department. Am J Heal Pharm. 2005;62(17):1793-7.

25. Mutnick $A H$, Sterba KJ, Peroutka JA, Sloan NE, Beltz EA, Sorenson MK Cost savings and avoidance from clinical interventions. Am J Heal Pharm. 1997;54(4):392-6.

26. Lewis PJ, Dornan T, Taylor D, Tully MP, Wass V, Ashcroft DM. Prevalence, incidence and nature of prescribing errors in hospital inpatients: A systematic review. Drug Safety. 2009;32(5):379-89. Cited Dec 102018.

27. Bates DW, Boyle DL, Vander VMB, Schneider J, Leape L. Relationship between medication errors and adverse drug events. J Gen Intern Med. 1995;10(4):199-205.

28. Alomi YA, Alghamdi SJ, Alattyh RA, Elshenawy RA. The evaluation of pharmacy strategic plan in past 2013-2016 and forecasting of new vision 2030 at Ministry of Health in Saudi Arabia. J Pharm Pract Community Med. 2018;4(2):93-101.

29. Alomi YA. National Pharmacy Administration Programs at Ministry of Health in Saudi Arabia. BAOJ Pharm Sci. 2015:1(9) 